\title{
The Clinical Significance of Patient Specimen Transport Modality: Pneumatic Tube System Impact on Blood Gas Analytes
}

\author{
Louanne M Carabini MD, Jacob Nouriel, Ricardo Diaz Milian MD, Erin R Glogovsky MSc RRT, \\ Robert J McCarthy PharmD, Thomas G Handler RRT, and Michael L Ault MD
}

\begin{abstract}
INTRODUCTION: A pneumatic tube system (PTS) is a cost-effective, rapid transport modality that utilizes induced pressure changes. We evaluated the clinical importance of 2 transport modalities, human courier and PTS, for blood gas specimens. METHODS: Following open heart surgery, 35 simultaneous pairs of arterial and venous blood gas specimens were analyzed from 20 subjects. Of each pair, one specimen was transported to the blood gas laboratory via a human courier and the other via a SwissLog PTS. Transport modalities were compared using the BlandAltman limits of agreement method. RESULTS: Compared with the walked specimen, the bias for $P_{\mathrm{aO}}$ was $-8.0 \mathrm{~mm} \mathrm{Hg}(95 \% \mathrm{CI},-40.0$ to $24.5 \mathrm{~mm} \mathrm{Hg})$; $P_{\mathrm{aCO}},-0.94 \mathrm{~mm} \mathbf{H g}(95 \% \mathrm{CI},-3.76$ to $1.86 \mathrm{~mm} \mathrm{Hg}) ; \mathbf{P}_{\mathrm{vO}},-0.60 \mathrm{~mm} \mathrm{Hg}(95 \% \mathrm{CI},-6.90$ to $5.70 \mathrm{~mm} \mathrm{Hg}) ; \mathbf{P}_{\mathrm{vCO}},-0.58 \mathrm{~mm} \mathrm{Hg}$ (95\% CI, -3.12 to $1.92 \mathrm{~mm} \mathrm{Hg}$ ) for the PTS specimen. CONCLUSION: The difference in the $\mathbf{P}_{\mathrm{O}_{2}}$ and $\mathrm{P}_{\mathrm{CO}_{2}}$ of paired (walked vs tubed) arterial and venous blood gas specimens demonstrated a slight bias. $\mathrm{P}_{\mathrm{aO}_{2}}$ values demonstrated the greatest bias, however not clinically important. Thus, PTS transport does not impact clinical interpretations of blood gas values. Key words: specimen transport; blood gas; cardiopulmonary. [Respir Care 2016;61(10):1311-1315. @ 2016 Daedalus Enterprises]
\end{abstract}

\section{Introduction}

Blood gas analysis is an essential tool in the evaluation of respiratory function and acid/base balance. In the acute care and perioperative environment, blood gas analysis results often guide an immediate clinical response. The

Drs Carabini, McCarthy, and Ault are affiliated with Northwestern Medicine, Department of Anesthesiology, Northwestern University Feinberg School of Medicine, Chicago, IL; Mr Nouriel is affiliated with Wayne State University School of Medicine, Detroit, MI; Dr Milian is affiliated with the Department of Anesthesiology, Georgia Regents University, Augusta, GA; Ms Glogovsky is affiliated with the Department of Respiratory Care, Riley Hospital for Children at Indiana University Health, Indianapolis, IN; Mr Handler is affiliated with the Department of Respiratory Care, Rehabilitation Institute of Chicago, Chicago, IL.

The authors have disclosed no conflicts of interest.

Jacob Nouriel presented a version of this report at the American Society of Anesthesiologist 2015 Annual Meeting, San Diego, California, October 24, 2015, in San Diego, California.

Funding for this study was provided by Northwestern Memorial Hospital Division of Respiratory Care and the Northwestern University Department of Anesthesiology. partial pressure of oxygen $\left(\mathrm{P}_{\mathrm{O}_{2}}\right)$ and oxyhemoglobin saturation in blood exist in a dynamic equilibrium. At low arterial oxygen partial pressures, small changes in oxygen tension significantly alter oxyhemoglobin values. Thus, accurate assessment of low oxygen tension is clinically relevant.

Transport time for specimen delivery to a centrally located laboratory is a significant variable in the pre-analytical component of total turnaround time. Transport time is largely dependent on transport modality. Before the introduction of the pneumatic tube system (PTS), specimens were delivered to the laboratory by a human courier. PTS is a cost-effective, rapid transport modality, reducing specimen analysis turnaround time. ${ }^{1-3}$ PTS is a series of tubes built into the hospital infrastructure that send patient specimens by the route of pressures both positive and negative relative to atmospheric pressure at a standard speed developed specifically for the system installed. PTS induced

Correspondence: Louanne M Carabini MD. E-mail: 1-carabini@ northwestern.edu.

DOI: $10.4187 /$ respcare.04809 
pressure changes must be considered as a possible source for pre-analytical error for blood gas measurements. ${ }^{4,5}$ Past investigations have observed that blood gases were not significantly altered when transported by PTS. ${ }^{6-8}$ However, when an air bubble is present within a specimen transported via PTS, the $\mathrm{P}_{\mathrm{O}_{2}}$ is significantly affected. ${ }^{9-12} \mathrm{~A}$ potential corollary is clinical misinterpretation.

Northwestern Memorial Hospital uses its PTS as the principle method for transporting supplies, paperwork, and patient specimens, including blood gas samples throughout the health care campus, which includes multiple buildings across 3 city blocks (approximately 0.18 miles). It is unclear whether clinically important changes occur to blood gas analytes in patient specimens transported via PTS. This prospective investigation will identify alterations in blood gas analysis in specimens transported by PTS compared with a human courier, the accepted standard. With proper sample collection within a clinical environment, we hypothesized that there is no clinically important difference between the partial pressures of oxygen or carbon dioxide $\left(\mathrm{P}_{\mathrm{CO}_{2}}\right)$ measured from blood gas samples transported via a human courier versus PTS.

\section{Methods}

This was a prospective, observational study for quality control measures to validate the use of PTS for transport of blood gas samples compared with a human courier. The study design was approved by the Northwestern University Institutional Review Board, Biomedical IRB. Written informed consent by all included subjects was obtained. Subjects were screened daily from the cardiac surgery schedule. Inclusion criteria included subjects scheduled to undergo invasive hemodynamic monitoring with arterial and pulmonary artery catheters. Additionally, these subjects required routine measurements of arterial and venous blood gas samples during their postoperative period in the intensive care unit. Exclusion criteria consisted of patients lacking arterial or central venous access necessary for blood sampling, patients with Methicillin-resistant Staphylococcus aureus, and immunocompromised patients.

Previous quality measures for accreditation with the College of American Pathologists had demonstrated a $\mathrm{P}_{\mathrm{aO}_{2}}$ standard deviation of approximately $4.5 \mathrm{~mm} \mathrm{Hg}$ from the national mean. Using the estimate for our institutional $\mathrm{P}_{\mathrm{aO}_{2}}$ standard deviation from the national mean, 40 pairs of blood gas samples (20 venous and 20 arterial pairs of whole blood samples) would result in a $95 \%$ CI of the limits of agreement of approximately $2.4 \mathrm{~mm} \mathrm{Hg}$, which is within the $27 \mathrm{~mm} \mathrm{Hg}$ range $( \pm 3 \mathrm{SD}$ ) of acceptable analytical performance. Therefore, we enrolled 20 subjects total with arterial and venous paired samples from each to achieve a spread of $\mathrm{P}_{\mathrm{O}_{2}}$ values within the clinical range of 50-200 mm Hg.

\section{QUICK LOOK}

\section{Current knowledge}

A pneumatic tube system is a rapid, cost-effective transport modality, utilizing both positive and negative pressures relative to atmospheric pressure. Previous studies of pneumatic tube system (PTS) transport of blood gas specimens have not demonstrated an effect of PTS on blood gas values.

\section{What this paper contributes to our knowledge}

Compared with human courier transport, transport of blood gas specimens via PTS utilizing maximal subatmospheric and superatmospheric pressures did not significantly alter blood gas specimen values within a perioperative clinical context. Additionally, PTS transport of blood gas specimens remains a rapid, cost-efficient transport modality irrespective of remote location specimen transport.

Simultaneous pairs of arterial and venous blood samples were drawn into standard 3-mm plastic blood gas Edwards Lifesciences Marquest Aspirator Syringes (Edwards Lifesciences Marquest, Irvine, California) containing 100 units of dried lithium heparin. Air was purged from each syringe per the manufacturer's instructions. One pair of arterial and venous blood gas samples was hand delivered to the blood gas laboratory while one pair of arterial and venous blood gas samples was sent to the blood gas laboratory in routine containers through the SwissLog PTS (SwissLog, Buchs, Switzerland) at ambient temperature from the furthest tube station on our health care campus. When both the walked and tubed samples arrived at the blood gas laboratory, samples were analyzed simultaneously at $37^{\circ}$ Celsius.

The Instrumentation Laboratories GEM Premier4000 analyzer (Instrumentation Laboratories, Bedford, Massachusetts) was used to analyze all blood gas samples to ensure standards of measure consistent with accreditation by the College of American Pathologists and the Joint Commission. Results, including blood gas measurements of $\mathrm{P}_{\mathrm{O}_{2}}$ and $\mathrm{P}_{\mathrm{CO}_{2}}$ collected and analyzed for each sample. The duration time of sample analysis was also recorded for each subject.

Data were tested for normality using the Shapiro-Wilk $\mathrm{W}$ test and compared between groups using a paired $t$ test. The agreement between the blood gas measurements from the samples hand delivered and the samples transported via PTS were determined using the Bland Altman limits of agreement (LOA) method. Statistical analysis was performed using RKWard version 0.6.2 and R version 3.1.2 


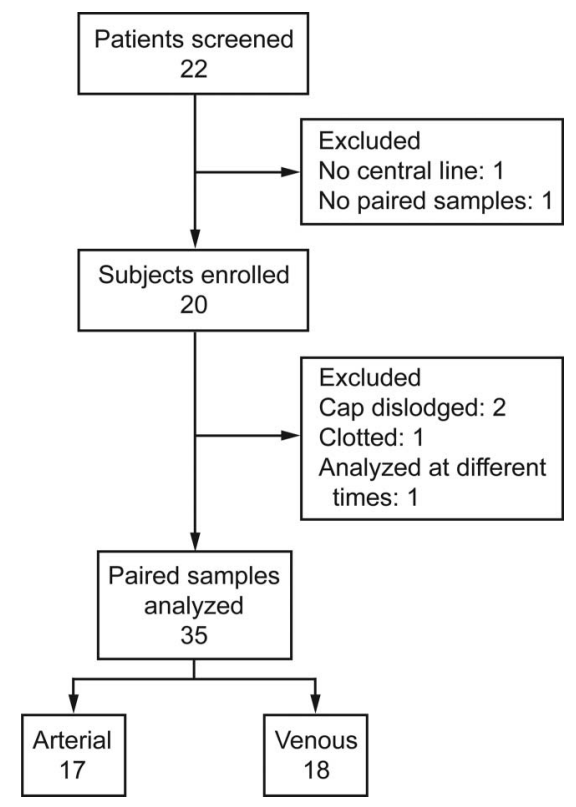

Fig. 1. Flow chart.

(The R Foundation for Statistical Computing, Vienna, Austria).

\section{Results}

Twenty-two patients admitted to the hospital to undergo cardiac surgery were screened for the study. Two patients were excluded before the samples were drawn: one because the anesthesiologist decided not to place a central venous catheter; the other because paired samples were not drawn simultaneously in the intensive care unit. One subject's samples were excluded from analysis, because the paired samples were not analyzed simultaneously. Two additional venous blood gas samples were excluded, because the cap was dislodged from the syringe during PTS transport. A second arterial sample was excluded secondary to clot formation before testing. Ultimately, 17 paired venous samples and 18 paired arterial samples were included in our analysis (Fig. 1). The time from sample acquisition to analysis was $9.1 \mathrm{~min}$ on average with a standard deviation of $8.8 \mathrm{~min}$ and a range of 3.8 to $25 \mathrm{~min}$.

The agreement between the $\mathrm{P}_{\mathrm{O}_{2}}$ and $\mathrm{P}_{\mathrm{CO}_{2}}$ in paired (walked or tubed) arterial and venous blood gas specimens was determined using the Bland-Altman LOA method. The 95\% LOA of the difference between paired measurements for the $\mathrm{P}_{\mathrm{aO}_{2}}$ was $-40.0 \mathrm{~mm} \mathrm{Hg}$ to $24.5 \mathrm{~mm} \mathrm{Hg}$ with a bias of $-8.0 \mathrm{~mm} \mathrm{Hg}$ (Fig. 2A). The 95\% LOA of the difference for $\mathrm{P}_{\mathrm{aCO}_{2}}$ were $-3.76 \mathrm{~mm} \mathrm{Hg}$ to $1.86 \mathrm{~mm} \mathrm{Hg}$ with a bias of $-0.94 \mathrm{~mm} \mathrm{Hg}$ (Fig. 2B). The $95 \%$ LOA of the difference for the $\mathrm{P}_{\mathrm{vO}_{2}}$ were $-6.90 \mathrm{~mm} \mathrm{Hg}$ to $5.70 \mathrm{~mm} \mathrm{Hg}$ with a bias of $-0.60 \mathrm{~mm} \mathrm{Hg}$ (Fig. 3A).
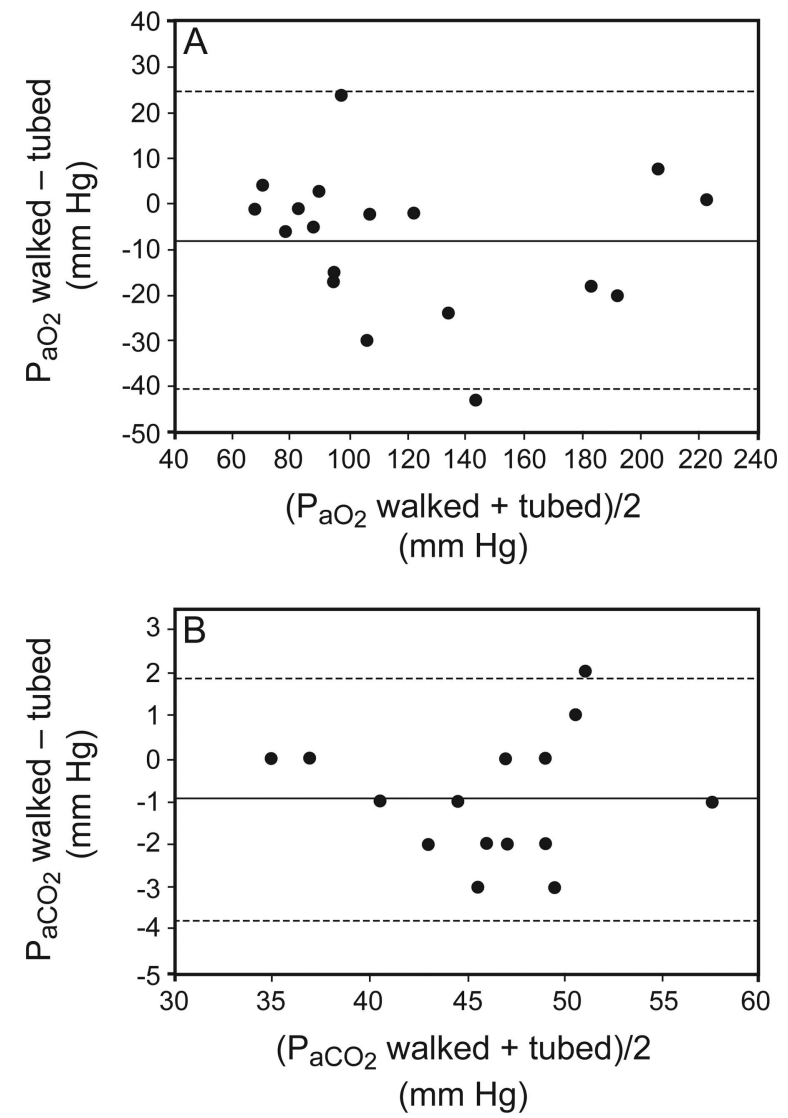

Fig. 2. A: Bland-Altman plot for paired measures of $\mathrm{P}_{\mathrm{aO}_{2}}$ transported via a human courier (walked) and a pneumatic tube system (tubed) in multiple subjects. The mean difference (bias of walkedtubed) was $-8 \mathrm{~mm} \mathrm{Hg}$ and is denoted by the center line. The $95 \%$ limits of agreement were between -40 to $24.5 \mathrm{~mm} \mathrm{Hg}$ as shown by dashed lines. B: Bland-Altman plot for paired measures of $\mathrm{P}_{\mathrm{acO}}$ transported via a human courier (walked) and a pneumatic tube system (tube) in multiple subjects. The mean difference (bias of walked-tubed) was $-0.94 \mathrm{~mm} \mathrm{Hg}$ and is denoted by the center line. The $95 \%$ limits of agreement were between -3.76 to 1.86 $\mathrm{mm} \mathrm{Hg}$ as shown by the dashed lines.

The 95\% LOA for the difference for the $\mathrm{P}_{\mathrm{vCO}}$ were $-3.12 \mathrm{~mm} \mathrm{Hg}$ to $1.92 \mathrm{~mm} \mathrm{Hg}$ with a bias of $-0.58 \mathrm{~mm} \mathrm{Hg}$ (Fig. 3B).

\section{Discussion}

This study was designed to assess clinically important differences in blood gas values, specifically $\mathrm{P}_{\mathrm{O}_{2}}$ and $\mathrm{P}_{\mathrm{CO}_{2}}$, for samples transported by PTS versus a human courier. The difference in the $\mathrm{P}_{\mathrm{O}_{2}}$ and $\mathrm{P}_{\mathrm{CO}_{2}}$ of paired (tubed vs walked) arterial and venous blood gas specimens was not statistically significant; however, the $\mathrm{P}_{\mathrm{aO}}$ demonstrated the greatest difference of all the sample groups with the samples transported via PTS having a higher resultant $\mathrm{P}_{\mathrm{OO}_{2}}$ on the Bland Altman analysis. 

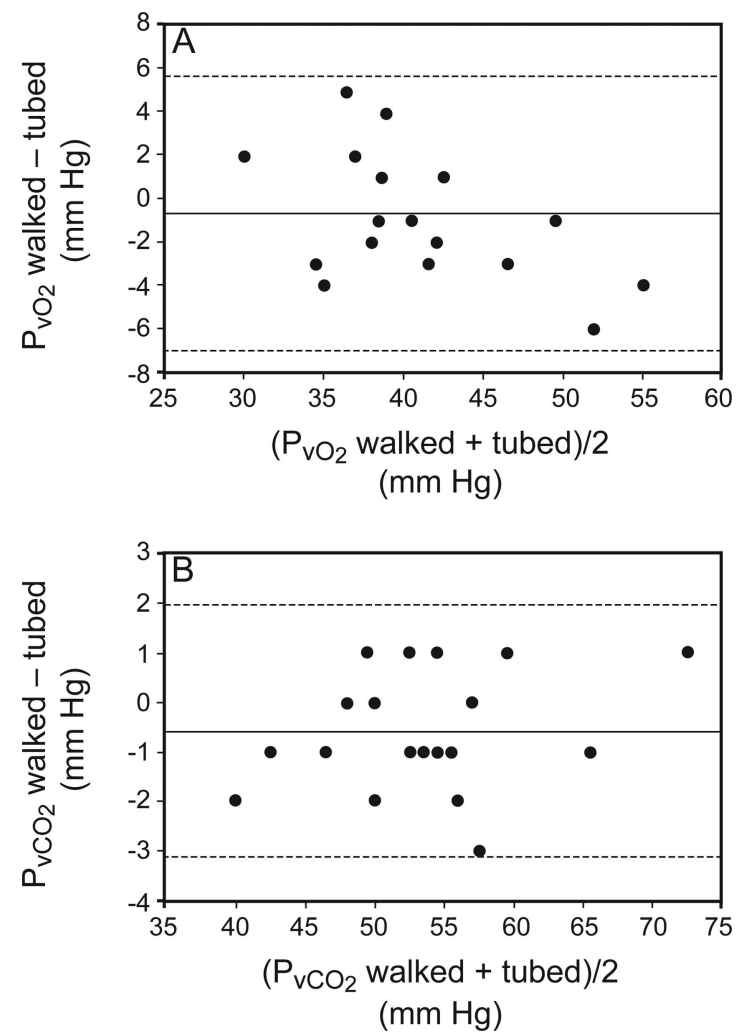

Fig. 3. A: Bland-Altman plot for paired measures of $\mathrm{P}_{\mathrm{vO}_{2}}$ transported via a human courier (walked) and a pneumatic tube system (tubed) in multiple subjects. The mean difference (bias of walked-tubed) was $-0.6 \mathrm{~mm} \mathrm{Hg}$ and is denoted by the center line. The $95 \%$ limits of agreement were between -6.9 to 5.7 $\mathrm{mm} \mathrm{Hg}$ as shown by the dashed lines. B: Bland-Altman plot for paired measures of $\mathrm{P}_{\mathrm{vCO}_{2}}$ transported via a human courier (walked) and a pneumatic tube system (tubed) in multiple subjects. The mean difference (bias of walked-tubed) was -0.58 $\mathrm{mm} \mathrm{Hg}$ and is denoted by the center line. The $95 \%$ limits of agreement were between -3.12 to $1.92 \mathrm{~mm} \mathrm{Hg}$ as shown by the dashed lines.

The $\mathrm{P}_{\mathrm{aO}}$ increase observed in PTS-transported samples was unexpected given the care taken to minimize air contamination within the sample syringes by purging the air and sealing with a rubber stopper per the manufacturer's instructions. The PTS on our campus uses a combination of negative and positive pressures relative to atmospheric pressures similar to many PTSs used in hospital facilities worldwide. Specimen transport under these conditions may explain the $\mathrm{P}_{\mathrm{aO}_{2}}$ increase. Ultimately, the difference is not statistically significant and is unlikely to result in altered patient care management.

Conflicting data have been published on the effects of PTS on specimen transport. In a study by Pragay et $\mathrm{al}^{7}$ potassium, acidic phosphatase, $\mathrm{pH}, \mathrm{P}_{\mathrm{CO}_{2}}$, and $\mathrm{P}_{\mathrm{O}_{2}}$ were not affected by PTS transport; lactate dehydrogenase was affected by PTS transport. Other studies have also reported that $\mathrm{pH}$ and $\mathrm{P}_{\mathrm{CO}_{2}}$ are not altered by PTS., ${ }^{4,13,14}$ Collinson et $\mathrm{al}^{4}$ compared blood gas samples sent in a pressure tight container through the PTS to arterial blood gas samples analyzed immediately in the intensive care unit. There was no significant difference in blood gas analytes between paired samples. However, other studies have observed that in arterial blood gas specimens contaminated by air, the PTS affected the $\mathrm{P}_{\mathrm{aO}_{2}}$ values. . $^{90,12,14}$ Notably, an increase of $10 \mathrm{~mm} \mathrm{Hg}$ or more was observed in samples with $\mathrm{P}_{\mathrm{O}_{2}}<85 \mathrm{~mm} \mathrm{Hg}$. Thus, care must be taken to remove air from blood gas specimens, especially when transported by PTS. Similar to our investigation, Keshegian et $\mathrm{al}^{6}$ assessed a wide range of $\mathrm{P}_{\mathrm{aO}_{2}}$ values in blood gas samples obtained from subjects undergoing cardiac surgery: they found an excellent correlation between specimens transported by PTS and those carried manually. Our study serves as an updated confirmation of their findings under the current practice of blood gas analysis and pneumatic tube transport.

These results support our data within a perioperative acute care environment. Other studies have utilized PTS transport from patient care areas, such as the operating room, intensive care unit, or emergency department, which may be in close proximity to the site of blood gas analysis. To our knowledge, no other investigation has emphasized the impact of PTS transport by choosing the maximal transport distance available on a large tertiary care medical campus.

The primary limitation of this study concerns sample size estimation. This estimation was determined objectively from proficiency testing samples supplied by the College of American Pathologists in the accreditation process of our blood gas laboratory. The $\mathrm{P}_{\mathrm{aO}_{2}}$ range for these samples was approximately 60 to $150 \mathrm{~mm} \mathrm{Hg}$. High $\mathrm{P}_{\mathrm{aO}_{2}}$ values $(>150 \mathrm{~mm} \mathrm{Hg})$ were observed in 4 experimental samples. Thus, our experimental samples represented a $\mathrm{P}_{\mathrm{aO}_{2}}$ range greater than the $\mathrm{P}_{\mathrm{O}_{2}}$ range of specimens used in the power analysis. This discrepancy led to the large $\mathrm{P}_{\mathrm{aO}_{2}}$ standard deviation for experimental specimens. Additionally, although we made an effort to remove all air from the blood gas syringes in this study, it is possible that air contamination remained. However, the subjects were in the cardiac-transplant intensive care unit with samples drawn and transported by experienced personnel, thereby representing a routine clinical environment for frequent blood gas analysis. Furthermore, it is important to emphasize the 5\% cap malfunction in the PTS group of samples that may have clinical consequences to routine use of this method of transport on a large scale health care campus. Lastly, this study assessed a specific PTS, and the results obtained may not agree with those of a different PTS, which may limit the generalized application of our results. 


\section{Pneumatic Tube System Impact on Blood Gas Analytes}

\section{Conclusion}

Timely, reliable blood gas analysis results are essential to cardiopulmonary patient management. According to our evaluation of transport modalities, samples transported in the hospital PTS are appropriate for clinical decision-making in the perioperative environment, when care is taken to minimize air within the blood gas specimen.

\section{REFERENCES}

1. Guss DA, Chan TC, Killen JP. The impact of a pneumatic tube and computerized physician order management on laboratory turnaround time. Ann Emerg Med 2008;51(2):181-185.

2. Winkelman JW, Wybenga DR. Quantification of medical and operational factors determining central versus satellite laboratory testing of blood gases. Am J Clin Path 1994;102(1):7-10.

3. Fernandes CM, Worster A, Eva K, Hill S, McCallum C. Pneumatic tube delivery system for blood samples reduces turnaround times without affecting sample quality. J Emerg Nurs 2006;32(2):139-143.

4. Collinson PO, John CM, Gaze DC, Ferrigan LF, Cramp DG. Changes in blood gas samples produced by a pneumatic tube system. J Clin Pathol 2002;55(2):105-107.

5. Baird G. Pre-analytical considerations in blood gas analysis. Biochem Med (Zagreb) 2013;23(1):19-27.
6. Keshgegian AA, Bull GE. Evaluation of a soft-handed computerized pneumatic tube specimen delivery system. Am J Clin Path 1992; 97(4):535-540

7. Pragay DA, Fan P, Brinkley S, Chilcote ME. A computer directed pneumatic tube system: its effects on specimens. Clin Biochem 1980; 13(6):259-261.

8. Poznanski W, Smith F, Bodley F. Implementation of a pneumatictube system for transport of blood specimens. Am J Clin Path 1978; 70(2):291-295.

9. Astles JR, Lubarsky D, Loun B, Sedor FA, Toffaletti JG. Pneumatic transport exacerbates interference of room air contamination in blood gas samples. Arch Path Lab Med 1996;120(7):642-647.

10. Biswas CK, Ramos JM, Agroyannis B, Kern DN. Blood gas analysis: effect of air bubbles in syringe and delay in estimation. Br Med J (Clin Res Ed) 1982;284:923-927.

11. McKane MH, Southorn PA, Santrach PJ, Burritt MF, Plevak DJ. Sending blood gas specimens through pressured transport tube systems exaggerates the error in oxygen tension measurement created by the presence of air bubbles. Anesth Analg 1995;81(1):179-182.

12. Mueller RG, Lang GE, Beam JM. Bubbles in samples for blood gas determination. A potential source for error. Am J Clin Pathol 1976; 65(2):242-249.

13. Steige H, Jones JD. Evaluation of pneumatic-tube system for delivery of blood specimens. Clin Chem 1971;17(12):1160-1164.

14. Zaman Z, Demedts M. Blood gas analysis: POCT versus central laboratory on samples sent by a pneumatic tube system. Clincia Chimica Acta 2001;307:101-106.

This article is approved for Continuing Respiratory Care Education credit. For information and to obtain your CRCE

(free to AARC members) visit

www.rcjournal.com 